This item was submitted to Loughborough's Research Repository by the author.

Items in Figshare are protected by copyright, with all rights reserved, unless otherwise indicated.

\title{
Craft, tangibility and affect at work in the microbrewery
}

PLEASE CITE THE PUBLISHED VERSION

http://dx.doi.org/10.1016/j.emospa.2014.03.001

\section{PUBLISHER}

(c) Elsevier

\section{VERSION}

AM (Accepted Manuscript)

\section{PUBLISHER STATEMENT}

This work is made available according to the conditions of the Creative Commons Attribution-NonCommercialNoDerivatives 4.0 International (CC BY-NC-ND 4.0) licence. Full details of this licence are available at: https://creativecommons.org/licenses/by-nc-nd/4.0/

\section{LICENCE}

CC BY-NC-ND 4.0

\section{REPOSITORY RECORD}

Thurnell-Read, Thomas P.. 2019. “Craft, Tangibility and Affect at Work in the Microbrewery”. figshare. https://hdl.handle.net/2134/26540. 
'Craft, Tangibility and Affect at Work in the Microbrewery'

Thurnell-Read, T. 2014. 'Craft, Tangibility and Affect at Work in the Microbrewery'. Emotion, Space and Society. 13: 46-54.

http://dx.doi.org/10.1016/j.emospa.2014.03.001

Dr Thomas Thurnell-Read

Department of Social Sciences

Loughborough University

Loughborough

LE11 3TU, UK

Email: t.thurnell-read@lboro.ac.uk 


\section{Craft, Tangibility and Affect at Work in the Microbrewery}

\section{Introduction}

In opposition to long running concerns about the nature of modern capitalism as organising conditions under which workers become alienated and estranged from their work (Arendt 1958; Marx 1959; Braverman 1974; Ritzer 1993; Sennett 1999; Hodson 2001), craftwork has increasingly been suggested as offering an appealing antidote to modern industrial production and rationalised service provisions based on mass consumerism (Dormer 1997; Sennett 2008; Crawford 2009). The (re)emergence of contemporary crafts has therefore been positioned as 'a collective response to industrialisation' (Metcalf 2002, 13) and as oppositional to the anonymity of disembodied mass-production; it is seen to offer a wider range of human rewards in both acts of production and consumption (Neopolitan 1986). Further, in recent years there has been a growing popular and academic interest in the reemergence of small-scale, locally produced products, with food in particular paving the way for new debates about the relationships between producers and consumers (Honore 2004; Wilk 2004; Kneafsey et al 2008; Paxon 2012). Products are desired by consumers, it is assumed, because they are made with skill and care by an identified person who utilises craft knowledge in their production meaning that product and process resonate with notions of quality and authenticity (Campbell 2005). As such, both consumer and producer are said to make a wide variety of 'affective investments' in such craft products (Evans 1998; Adamson 2007; Coombe and Aylwin 2011). Coupled with these developments, advances in qualitative research seeking to capture the vitality of the sensory, embodied and affective qualities (Pink 2009) of everyday life mean the time is ripe for further investigation of the experiences and subjectivities of skilled craft workers.

This paper explores these themes through a qualitative study of the occupational identity of brewers working in small-scale breweries in Britain. It is suggested that their engagement 
with both the product and the process of brewing illustrates important aspects of the embodied and affective nature of work. In particular, brewers' narratives foreground a sense of reward and satisfaction found in the production of what is perceived to be a product distinguished by the skills, passion and care deployed in its production. Research in the United States of America (Flack 1997; Daniels, Sterling and Ross 2009; Wesson and de Figueiredo 2001) and Australia (Holden 2011) have provided some empirical investigation of small-scale breweries. However, with the exception of recent work by Spracklen, Laurencic and Kenyon (2013) no studies have engaged with the British context in which the number of breweries operating has tripled in less than twenty years with the majority of growth coming from small-scale breweries (BBPA 2012). Further, such studies have tended to adopt a consumption focused approach where the practises surrounding the enjoyment and appreciation of the final product are foregrounded in place of the labours of the brewers themselves.

This article contributes to recent debates about the place of craft in occupational identity and workplace subjectivities (e.g. Crawford 2009). The notion of craft is deployed by many brewers as a means of expressing and occupational identity which weaves together accounts of both instrumental skill and subjective passion. By situating the notion of craftwork employed by brewers in a wider sense of occupational subjectivity which is informed by affective attachment and 'sensory work' (Hockey 2009), the article demonstrates how craft is emotive and embodied. The following sections explores first the re-emergence of an academic interest in skilled craftwork and the nature of work which emerge from considering the affective and embodied qualities of skilled craft work. After a contextual and methodological section, an initial analysis then outlines some main themes in how interviewees accounted for their development of a brewer identity as expressed through notions of skill, competence, knowledge and passion. This is then developed in reference to two forms of tangibility identified in the brewers' narratives of occupational identity; tangibility of process and tangibility of outcome. These finding, it is suggested in the conclusion, 
highlight important ways in which craft based labour can be understood as embodied, affective and, as such, integral to current debates about the nature of work in modern society and, of late, increasingly uncertain and unstable times.

\section{Craftwork rediscovered}

The idea that modern forms of work are lacking in beneficial human qualities such as individuality, creativity and autonomy has a long history in social theory and sociological research. Karl Marx's (1959) conception of alienation involved, as two of four forms of alienation, the estrangement of the worker from both the product and the process of their own labour. Thus, workers have little input into the design and creation of the products they produce beyond a series of repetitive tasks. Similarly, Hannah Arendt drew a distinction between homo faber and animal laborans, where the former stood for work in its ideal typical and intrinsically enriching form characterized by skill, creativity and autonomy, and the latter stood for the base labour, characterised by mere economic motivations, that she feared would become pervasive with the advance of modern capitalism (Arendt 1958). More recently, Ritzer (1993) develops a picture of modern service orientated work as repetitive, calculable and rational. In such a climate of control and predictability there is, we would assume, little opportunity for the caprices of the creativity or passion of individual workers. Further, while the development of the service sector has frequently necessitated the performance of 'emotional labour' (Hochschild 1983), such is readily seen as an ersatz sociability where scripted 'have a nice day' platitudes replace genuine affective investment in one's work. Indeed, in late modernity, work and labour, increasingly beholden to an ethos of market led flexibility, might be seen as no longer offering the solidity of identity that they used to and that workers struggle to build a sense of their own character and integrity around their work (Sennett 1998). 
Against this backdrop, the recent revival of academic interest in the labour of individual skilled craft workers by the likes of Richard Sennett (2008) and Matthew Crawford (2009) raises some pertinent issues, the analysis of which offer considerable insights into the nature of contemporary work and workplace subjectivities. Central to both Sennett and Crawford's accounts is the notion that in craftwork we find interesting details regarding the subjectivities of how individuals relate to their own labour as a process of embodied and affective engagement which, ultimately, speaks to a wider understanding of the rewards and satisfactions of work and, at an even more general level, personal identity. In spite of its age, an instructive case is found in Inkson's (1987) study of potters in New Zealand. He observed that craftwork is idealised for its intrinsic value; the 'practice of craft gives meaning to the work, facilitates the development of skills, engrosses and delights the worker, gives pride in personal achievement, exercises and extends the creative faculty, and establishes the worker as the controlling agent in the process of work' (Inkson 1987, 163). Thus, the perceived rewards of craftwork relate to the worker being in closer contact with and having greater control over their work.

Starting with a relatively broad definition of craft as 'a form of skilled labour that is qualitydriven, materially specific and motivated by internal, as well as external, rewards' (Banks $2010,307)$, it is possible to identify certain key characteristics of craftwork. Craft is associated with knowledge, skill and personal control learnt and developed over time and applied to a particular material or materials (Dormer 1997). While craft workers may work in individual isolation or in a range of institutional and collaborative settings, they tend to value, but may not be able to unproblematically achieve, autonomy in relation to their working practices and their creative input to the production process (Banks 2010). Indeed, craftwork will frequently involve creativity both in the sense of attempting to create something unique and novel but also in a more mundane sense of the creating something from base ingredients. In this process of making, as explored below, craft workers will necessarily deploy not just physical skill but tacit knowledge (Polanyi 1967) which, acquired through 
often extensive practice and training, allows for the feeding off of a range of bodily and sensory stimuli to know what to do and, intuitively, when to do it (O'Connor 2005).

In contrast to the typical industrial worker as identified by Marx (1959) as estranged from both the product of their labour and the processes which they themselves form only a small part of, the identity of the craft worker is seen as manifest in the product of their craft. Thus, it has been suggested that craft provides processes and challenges that allow one to better understand oneself through one's work, through the accomplishment and failures manifest in successful or unsuccessful objects which result from one's own efforts (Needleman 1979). The craft producer, as Colin Campbell observes $(2005,27)$, is therefore someone "who invests his or her personality or self into the object produced'. Similarly, in her study of artisanal cheese makers in the USA, Heather Paxson $(2012,72)$ discuses such craftwork as a form of 'engaged labour' where craftspeople care about the work they do 'because their identity and sense of self-worth are tied up in doing a job well'. As such, while many craft occupations may involve the production of relatively quotidian objects, those objects are carriers of meanings and of the identity of the maker. That these craft objects are seen as manifestations of the maker's identity - be it a fine piece of pottery, an artisanal cheese or, as this paper will suggest, a carefully crafted pint of ale - therefore represents the culmination of a coming together of both the corporeal and cognitive skills of the maker with the materiality of ingredients, tools and equipment and the spaces of production.

Craft is therefore a term deployed by many of the brewers themselves in their interview while craftwork is a concept used by the author to bring together these historical and contemporary debates concerning the mutual connections of work, identity, skill and various types of knowledge. While, as noted below, 'craft beer' has become a contested concept amongst beer consumers and producers, craft and craftwork, as this article suggests, are of considerable analytical use in deriving more nuanced understandings of particular forms of labour which are characteristically embodied and sensory. Indeed, it is the embodied and 
sensory nature of craftwork that distinguish such by its tangibility from more abstracted mental labour.

\section{Embodiment, affect and the rewards of work}

Importantly, it is through its physical and embodied nature that craftwork is seen to highlight important aspects of labour. Occupational identity and occupational competencies can be shown as a complex amalgam, a bringing-together of skills, knowledge and both embodied and emotive connections to place and practice (Author A). This confluence of different elements of occupational identity is particularly evident in tasks such as those of the craft worker. The development of a craft worker identity has therefore been seen as a process of gaining the correct experience and knowledge, owning materials and tools and acquiring and displaying skills competencies (Dickie 2003). Further, studies of craftwork have contributed to developing understandings of the embodied, corporeal and tacit aspects of how skills and knowledge are put into practice. Erin O'Connor's (2005) autoethnographic study of learning the craft of glassblowing is thus illuminating in drawing attention to the complexities of bringing together instrumental, sensory and tacit forms of knowledge in the pursuit of proficiency in a given craft practice. Such developments seek to re-embody our understandings of work and draw attention to how bodies are 'at work' in a range of occupational settings (Wolkowitz 2006). Likewise, John Hockey (2009) has suggested the need to give due importance to the sensory aspects of work and the competencies developed through smelling, touching, tasting and hearing. Significantly, these sensory aspects of one's work are not separated off from more instrumental, cognitive, forms of knowledge and knowing but are, commonly, an integral part of performing a particular labour competently. It is therefore important that workplace knowledge is understood not as an abstraction but as 'ongoing and situated practices of knowing as part of their interaction with the social and material world' (Berner 2008, 321). 
While many studies of craftwork have focused very closely on the actions of craft, of the putting into action the physical movements that constitute skilled work, this article utilises craft as a means of accessing a set of wider insights into the nature of work and worker identity. As explored below, the brewers understand their work in the brewery as an expression of their own identity. Such accounts seek to broaden the scope with which knowledge and forms of knowing are conceived of in the action and practice of work and, ultimately, to enliven our understandings of the tacit aspects of work. While, as noted, very few studies of brewery work exist, there are some interesting parallels to be made with the more sizable body of literature addressing the occupational identity of chefs and professional cooks (Fine 1996; Gunders 2008; Palmer et al 2010; Robinson and Beesley 2010). Indeed, as is explored below, several participants of the current study drew their own parallels between the work of brewers and that of chefs. Professional chefs, therefore, are seen to develop and perform a specific identity which draws on concepts of skill and competency, of the material and affective environment of the kitchen, and of the output of their labour in the form of food which is acknowledged and appreciated by others (Palmer, Cooper and Burns 2010). Professional chefs prioritise creativity in both a sense of innovation in creating something new and unique but also in a more everyday sense of 'creating' something through the skilled selection, preparation and combinations of ingredients and materials (Robinson and Beesley 2010). The occupational identity of professional chefs is therefore a complex one, for it is formulated across physical space (the kitchen) and material objects (raw ingredients, plates of food, cooking utensils) and, in the cuts, burns and general signs of fatigue written upon the body 'has a physical as well as a psychological dimension to it' (Palmer, Cooper and Burns 2010 318). As the following analysis will demonstrate, brewers also construct a similarly complex set of workplace subjectivities and it is here that the paper draws insights into the nature of work and work identity as affective and embodied.

\section{Context and methodology}


The findings presented in this article come from a set of in-depth qualitative interviews and brewery visits conducted as part of a wider research undertaking exploring the changing tastes and practices of beer consumption in Britain (Author B). The article therefore is situated in a wider context characterised by what has been termed a British Real Ale revival. 'Real Ale' is a term coined by the consumer pressure group The Campaign for Real Ale (CAMRA) in 1971. 'Real Ale' was from the outset defined by CAMRA as a beer produced according to traditional British, but at the time apparently moribund, methods which allowed for a secondary fermentation in the vessel from which the beer is served, this being either a cask or bottle. Further stipulations outlined by CAMRA prohibited the addition of extraneous gases as had become and are still common in most mass-produced 'keg' beers and lagers where the beer is pasteurised, filtered and then re-carbonated before dispense and consumption. Although Real Ale, thus defined by CAMRA, was still available during the early years of organisation's existence, it was often considered to be of bad quality, served in poor condition and, due to being a low commercial priority of the large breweries dominating the industry, seen by CAMRA as being under threat of extinction (Protz and Millns 1992; Protz 2011). While divergent uses of the term ale exist, such as the historical definition where the terms ale and beer refer to hopped and un-hopped drinks respectively, this CAMRAespoused conception has gained considerable purchase and is readily recognised amongst many British beer drinkers.

As noted above, the terms craft and craftwork are deployed in this article to make sense of a range of features of work in small breweries which are characterised by embodied, sensory and emotive qualities and are understood by those who undertake such work as being geared towards values concerning quality, care, passion, skill and attention to detail. The term craft was used by many, but not all interviewees, and the author further elaborates on the concept by drawing on the academic literature on craftwork so as to analyse and explore these themes. It is, however, important to note that 'craft beer' has in recent years become an at times fiercely contested term amongst CAMRA members and beer consumers more 
generally. Many 'craft beers' are cask conditioned or available in cask versions, yet a growing number, while made with apparent care and skill, are not and are therefore not, by CAMRA definitions, Real Ale.

Recent decades have seen a considerable growth in the number of breweries operating in the United Kingdom, with the figure passing 1100 in 2013 (Protz 2013) and representing a 70 year high and a notable increase from 493 in 2003 and 396 in 1993 (BBPA 2012). This growth has largely been driven by the growth of small breweries which have recently been opening at a rate of 50 a year (Wainwright 2011). The continued success of Real Ale, albeit in a general climate of attrition with pub closures and falling beer consumption, is most notable in the rapid growth of these small-scale breweries. This growth has, in no small part, been facilitated by the 2002 introduction of a sliding scale of excise duty paid on beer produced by smaller breweries. The term microbrewery originated in the UK during the 1970s and was used primarily to describe the new trend in small scale, and at times rudimentary, breweries opening at the time typically run by no more than a few people and producing relatively small batches of beer. While this loose terminology remains in common use in the UK, in the United States the term has a more specific meaning as defined by the Brewers Association of the United States as a brewery producing less than 15,000 US standard brewer barrels a year (Oliver 2011). This more precise meaning as quantified in terms of output rates is, however, in far less common use amongst the majority of consumers who, instead, appear to recognise the term as cogitating a brewery which is small in scale, independently run and largely local, rather than national or international, in its operational reach.

While interviewing brewers about their work originated as a means to better understand consumer practices, it became evident from the first interview that brewers occupied a valued position at the juncture of production and consumption practices. This article offers an analysis of twenty semi-structured qualitative interviews conducted at various breweries 
between July 2011 and August 2013. Breweries were, based on practical necessities, predominantly selected for their proximity to the researcher, being situated in and around the counties of the West Midlands and Warwickshire in central England, although two interviews were conducted with breweries in the Southwest of England and two took place in London in order to include more rural and more metropolitan examples respectively. Thus, the breweries occupied a range of locations from rural, suburban to metropolitan areas. One interviewee did not brew himself, choosing instead to employ a full-time salaried head brewer leaving him free to focus on product development and marketing while a further interviewee, a former brewer of considerable experience, now runs a successful business designing, fabricating and installing breweries. The smallest scale producer used a setup with a capacity capable of producing the equivalent of two and a half British 36-gallon brewery barrels per brew, while the largest was head brewer for a regional brewery with a modern complex capable of producing 50,000 barrels a year. Of the twenty, all were male with the one exception of a female brewer while ages ranged from mid-twenties to late-fifties with most being in their forties or early fifties.

Interviews lasted between forty minutes and an hour and a half and were recorded and later transcribed verbatim. The resulting transcripts were coded and analysed for emerging themes relating to motivations, skills, craft and occupational identity. To ensure anonymity, all interviewees were given pseudonyms and, where possible, descriptive features such as the specific names of breweries and beers have been avoided. Interviews took place in the breweries or in adjacent offices (and, in one case where the recently opened brewery had yet to acquire a second office chair, sitting on a beer cask for the duration of the interview). As is discussed below, the spatial and material qualities of the breweries often acted as a stage or backdrop to the interview with many brewers insisting on a tour of their equipment and ingredient stores before, and in a few instances during, the interview. As such, the research was informed by Sarah Pink's (2009) work on 'sensory ethnography' and while the 
interview narratives of the brewers form the centre of the analysis important insights were also drawn from this broader understanding of the brewery as an affective space.

In addition to the twenty interviews a range of other methods were employed to gain a qualitative insight into the nature of work in breweries. This included participating in four brewery tours, several 'meet the brewer' nights hosted at local pubs and a 'brew a beer day' where participants shadow the brewer and assisted with the brewing process. Further documents were also collected including marketing materials for breweries of various sizes, visual and textual content of brewery websites and various online blogs and beer appreciation websites. Lastly, worth noting is the author's own experiences of small scale 'home-brewing' which, although humble and at times remarkably variable in success, helped provide a functional understanding of the stages of the brewing process and the terminology of the brewery which proved useful in establishing rapport with participants during interviews (Hammersley and Atkinson 2007).

\section{Craft at work in the brewery}

\subsection{Skills, Knowledge and Passion}

Throughout the interviews, research participants were given the opportunity to develop an account of their occupation identity and to explain what features they saw as most important to their work. In terms of being a successful brewer, two themes were predominant. Firstly, brewers spoke of the process of acquiring and putting into practice knowledge and skills. Thus, a detailed understanding of the brewing process coupled with the proper use of materials, ingredients and equipment were seen as prerequisites of success in the trade. Secondly, a more subjective, affective and impressionistic sense of passion for the craft was evident in all interviewees' accounts. This initial section, therefore, outlines how the craft of brewing was seen by brewers as a complex combination of skills and passion where one 
enacts and enables the other, the suggestion being that a lack of either would make it impossible to produce good Real Ale.

An initial focus of interviews was on how brewers had come into the brewing trade and how and by what means they had developed the skills required to produce the product of a required level of quality. Two interviewees had acquired and one was in the process of acquiring a postgraduate qualification in brewing from a particular Scottish university noted for its courses in brewing and distilling, while three had acquired their skills primarily though on-the-job training during previous employment with larger breweries. The majority, however, had led a more eclectic approach in collecting the skills and experiences required for their work including short vocational courses and both formal and, often, informal apprenticeships at established breweries. For example, Steve expressed how knowledge and skills were developed over time and acquired from a range of sources:

'Basically, when you're into a subject you pick up a lot of knowledge, you read around the subject and obviously you drink beer. Twenty years of doing that is your background knowledge. Then when you say right, I'm going to properly look into this, I started home-brewing which is absolutely vital to do to give you some practical experience just to get a handle on how difficult it is. It's very difficult to brew on a small-scale. It's invaluable to do that even before you've done commercial training. I did that then went on a commercial brewing course which is only sort of four days but it's a very effective course there's just enough technical knowledge that you need but most of it is practical and hands on'

Here, the interviewee is typical of many of those interviewed in that knowledge is sought out from a range of sources both theoretical ('you read around the subject') and, in homebrewing, practical. Similarly, Gus spoke of a period before setting up his brewery where he was preoccupied with 'literally filling the garage and shed with every bit of brewery kit and 
equipment' he could 'lay hands on' and producing home brewed beer for family and friends 'for the slightest reason, a birthday, Christmas, bank holidays coming up, get a brew on and make something tasty for everyone to drink with the barbeque'. As noted by Dickie (2003), the craft worker identity is sustained through the engagement with the correct assemblages of materials, tools, equipment and skills.

It was notable that most brewers interviewed had, prior to the initial setup of their own brewery, managed to shadow an experienced brewer or, in many cases, use an established brewery to test brew their recipes and hone their skills. Indeed, many spoke of this as of greater help than more formal training. Phillip spoke candidly about his experience shadowing a more established brewer:

'He took me under his wing, you know. I'm not saying he let me root through his brewery log and nick his recipes but I watched him at work, learnt from his experience, learnt what it takes to make a cracking beer [...] From how into it all he was, well that got me buzzing, you know'

Likewise, Scott, one of the younger brewers interviewed, spoke of having gained initial experience in the trade at a more established brewery:

'I worked in [another London brewery] for about a month just for free, you know, I emailed a lot of the London breweries around about January that year when I knew I was coming back just asking if I could basically spend some time brewing with them, I had a great response actually, from about ten emails about eight all said yeah come and have a chat...So I went to [the brewery] when I got back [from working in Australia], did three or four weeks there, watching the process, clearing basically yeah, but at the same time asking questions, you know the guys there were great, it 
was good to understand how the beer is made, how to build a brewery, what you need to get done'

Interestingly, in complement to specific skills, Scott also spoke of the importance of just 'hanging out' at the brewery and picking up on the atmosphere. Being around a working brewery and seeing how things 'get done' thus appeals to a sense of tacit knowledge, that simply being in and around the brewing process invests the brewer in the making with a wider sense of the brewery at work.

Woven into these accounts of acquiring the correct craft skills, knowledge and equipment was a more general emphasis on passion. Brewers narrated their readiness to place quality and craft over other concerns. Many spoke of not taking profits or pay from the company for up to two-years following start up, the implication often being that their sacrifice was testament to their passion and commitment. Likewise, they would give examples of how cutting out more expensive ingredients or pasteurising and kegging their beer would result in greater profits or ease of sale but, again, placed emphasis on their passion above profit. Such bears some similarities to Coulson (2012) who notes that musicians are frequently willing to forego financial rewards and instead draw fulfilment from the act of performing and of being part of a music scene, community or subculture.

Many of the brewers spoke of how their own passion for beer ought to mirror that of their customers. For example, Phillip reflected on 'meet the brewer' nights where local Real Ale pubs invite brewers to come and speak to beer enthusiasts as an important moment to demonstrate his knowledge and 'care' for beer:

'At first I didn't like the meet the brewer thing much but, you know, you get better at it and people want to talk to you, know about the guy who makes their beer. Just an old bugger like me but they want to see how much you know about the beer, how much you care about the beer [laughs] yeah you get to show off a bit too' 
Here Phillip speaks of needing to demonstrate his knowledge and passion to customers eager to engage with his products. Indeed, many brewers acknowledge that they are part of the product in that consumer's desire and actively seek out products made by a recognised person who demonstrates knowledge, passion and commitment to their craft. This may indeed be shared with a wider range of enterprises where passion in one's work has been linked to increased motivation, improved satisfaction and wellbeing in the workplace (Forest et al 2011; Murnieks et al 2012; Bennett 2013).

It was evident that this passion was worn as a badge of authenticity particularly in relation to the large breweries that were derided as purely economy focused, profit-driven, enterprises and also in contrast to more recent entrants into the brewing industry who were seen as trying to 'jump on the band wagon' rather than necessarily further a passion in ale. The following two interview extracts typify this in demonstrating how, first, knowledge without passion and then, second, passion without skill and knowledge where seen as resulting in a failure to produce the correct and proper Real Ale brewer identity:

Jonathan: 'That's one of the things ultimately, it's the enjoyment of beer. I am slightly concerned some times when you see some of the new breweries coming out and the people are, well, they might be very good brewers but they're not passionate about beer. And there are some that god forbid that don't even drink Real Ale, it's shocking [laughs] there's nothing to stop you technically being able to brew good beer, if you follow the rules. You know, but I think the thing that differentiates a lot of us is the passion for beer'.

Duncan: 'Some of the craft brewers it's sometimes an extension of a hobby and sometimes it's an avid CAMRA member that just takes his hobby a bit further. Quite often these people do not have the knowledge to do it properly, they're ok when things are going well then you have a problem and they start to struggle' 
As such it becomes evident that the development of a 'correct' brewer identity involves the acquisition of instrumental skills and knowledge coupled with and balanced by the invocation of a more subjective sense of passion and strong emotive investment made in the beers produced.

The following extended interview extract from Richard captures this narration of the occupational identity of brewers:

'After I qualified as an engineer I spent five years as a draftsman, which is horrible, stuck in an office. So, I did a bit of work on farms, I always preferred manual work, to be fair, worked on farms and I had a business restoring old cars. As I say, seventeen years in I spent in the probation service, don't know how I ended up there, that did give me time to source the, you know, to research the brewing side. And I started part-time. I kept my job in the probation service as a part time and started the business part time. And it was 2002 I thought well make a full go of it. Yeah, it's so different, so diverse and not just the brewing the other side of things. That's the down side. The best bit is the actually production of the beer, the brewing process. I'd happily do that all day and every day [...] It's fantastic, you are creating something and it's even better when you're doing it for a living when you can go into a pub and it's got your beer and just observe people drinking your beer, it's great [...] Yeah, yeah, I don't announce who I am I just sit back and observe people enjoying your product and it's great when you're looking at it, but as regards the brewing side, to me, the best thing in the world is the end of the brewing day about 7.30 in the evening when you go into the brew house and the yeast just starts to work, the first aromas, that's absolutely fantastic, l'll never tire of that'.

This extract is worth quoting at length for several reasons. The interviewee demonstrates how his identity as a brewer is integrated into a wider biographical account where his current 
work is contrasted favourably to his previous occupations. Such biographical narratives of working lives are intriguing sources which provide rich insights into constructions of selfidentity (Watson 2009). Significantly, Richard appears to narrate his entry into the brewing industry as a return, following years 'stuck' in disembodied office work. This appeared as a common feature in many interviewee accounts of their entry into the brewery industry. As such, Daniel expressed how he had 'totally had enough of office life' after years working in the automobile industry and a considerable period of relative instability spent working on short term contracts as a consultant. Scott spoke of being 'disillusioned with contracting, especially expatting' in his role as a civil engineer which had taken him to East Africa and Australia in recent years. Similarly, Frank, having spent much of his 20 s in local banking decided that he was 'incredibly unhappy with banking, with the office world' and, on seeing an advert for an assistant brewer at a local brewery 'phoned up and said you're advertising my job, it's $M Y$ job'.

Bill, reflecting on his experience of installing breweries for numerous new microbreweries, observed that:

'Most people never get bored making beer, it's a very interactive and joyous thing to do, you know, the creation of beer is such that if you're moderately successful at it's a rewarding job. I've had people come to me who just want to change their lifestyle, they're just fed up, they want to be a bit more creative, less intense, you know, it's surprising how many people jack in quite good jobs to take on brewing because, well, it's the lifestyle'

Returning to Richard's description detailed above, he captures well the rewards of his trade by focusing on two elements. First, he notes the appeal of being able to watch people consume and enjoy the product which he himself has produced. Second, in a way reminiscent of the potters in Inkson's $(1987,169)$ study who derived considerable satisfaction from the 'feel of the clay', he emphasises the embodied and sensory rewards of 
the process itself. Having here outlined some key themes emerging from the interview data relating to how the correct brewer identity is established through knowledge and skill but also passion, the following sections will further consider the suggestion that the occupational identity of the brewers interviewed is notable constructed around the tangible aspects of their craft. This shall be divided between the tangibility of process and the tangibility of outcome.

\subsection{Tangibility of process}

The hands-on, practical, nature of brewing was frequently emphasised by brewers during interviews. Specifically, particular illustrations of affect can be found. Frank, for example, observes that:

'I wish I could say that I have all the qualifications in the world and started out when I was 17 years old as a career brewer, but you get a gut feeling and I can do what we do here, well. I've not done as much research as I'd have liked to, I chat to a few brewer friends and they're not arm chair brewers but they get a fair bit more time than me, whereas I have always preferred to be hands on because it helps with it helps with keeping an eye on things, so many things can go wrong. But ultimately I know I do it well, the beer is good, you know, and you get that feel for it, for what works'

Frank's explanation of his 'gut feeling' for his work is insightful. While it is characteristically biographical in being phrased as a reflection of his position in the industry and his identity as a brewer, it also draws on numerous expressions of affect and immediacy which are evidently important to his work but, perhaps, are never quite adequately expressed in verbal narrative accounts. Rather, the process itself is evidently a combination of embodied emotions and feelings relating to the 'sense' of doing a job well which, here invoked as 'gut feeling', are difficult to express in verbal accounts alone. 
This aspect of the occupation was often demonstrated during brewery tours which were offered by most breweries in some form ranging from a regular visitor tour at a fixed time with an entrance fee covering the cost of the tour and sampling various beers to a more informal sense of interested customers, in Jason's words, 'popping in to take a look at the kit'. During such tours, visitors are commonly given a short history of the brewery and an explanation of the brewing process. Visitors' attention was invariably drawn to stores of ingredients and often invited to crunch grains of malt between their teeth or to roll a few heads of hops between their fingers then smell the resinous oils. Evidently, this 'fascination with the material' (Racz 2009, 58) allowed the brewer to express sensory aspects of the brewing process and to enact embodied knowledge about the processes of production. Additionally, in light of Berner's $(2008,321)$ suggestion that working knowledge and skill ought to be seen as a performative 'practical achievement' whereby work is both demonstrated and brought to life through its performance in front of others, the brewery tour is evidently an opportunity for the brewer to demonstrate the accomplishment of their practical competencies.

When Adamson $(2007,168)$ speaks of the 'seductive aspects of craft' where 'the hot and sweaty theatrics of the glass hot shop, the fountains of wood shavings produced by turners at the lathe, the magical transformations that occur on the pottery wheel' he identifies the physical, material and affective appeal of 'craft-in-process'. As in Richard's account above, the brewery has its own unique configurations of smells, sounds, touches and noises which evidently appeal greatly to the brewers interviewed. Notably, many interviewees spoke of the merits and enjoyments inherent in the activity of brewing. Thus, what Evans $(1998,85)$ refers to as 'the sensual satisfactions of craft activity' are apparent in the accounts of many of the brewers interviewed who readily spoke of the tastes, smells, sights and sounds of the brewery and the brewing process. Further still, as in Frank's 'gut feeling', craft skills often draw on tacit knowledge which is often easier to demonstrate than it is to explain and describe verbally (Polanyi, 1964; Dormer, 1997). Thus, as well as verbal explanations during 
the interview, it was common for brewers to insist on showing me around the brewery before the interview. Gus, for example, spent some time patting three fermentation vessels in turn saying 'that's where the magic happens' and that 'on any one day we can have our bitter in here, a pale ale in here and a stout in here, it's just lovely'.

The practical nature of the job and, in particular, the tangibility of the process was often contrasted with other occupations involving a more disembodied and abstracted relationship with one's labour. One brewer, Geoff, drew such a comparison by noting the stress of his previous career as a further education lecturer.

'Right, well I ended up as senior lecturer with very few contact hours and hating the job really. It became paper work I was on endless internal review panels judging other lecturers and giving them performance marks and things like that which I really didn't enjoy. Plus, the politics of education had changed and really I was, as most of my colleagues were, under a lot of stress and not everybody admitted that and I think I just went through years and years of stress without realising it and it catches up with you in the end and that used to tire me out, the mental stress of the job. Now, it's the physical side of this job that tires me out and it is taking a toll on my body because it's all lifting 25 kilo sacks of grain, it is full nine gallon casks of beer. So, I mean, that's taken a bit of a toll, but I don't have any stress any more. It's almost like I've gone back to the land and you've got out of the rat race'.

Here, the disembodiment of the previous career is contrasted with the physical work of the brewery. Further, the interviewee's account of the 'stress' of his previous career suggests that, in comparison, his new life as a brewer is more tangible and fulfilling precisely because his labours can be felt physically on and through his body.

\subsection{Tangibility of outcome}


In his 1930 work The Conquest of Happiness, the British philosopher Bertrand Russell (2006) reflects that the types of work which carry the greatest capacities to foster happiness are those which require skill and which involve, defined in a very board sense, construction. Work was, for Russell, most meaningful and most likely to lead to happiness when it involved constructing something ordered and tangible from disorder. Great satisfaction, it is suggested, is derived from work where the worker can clearly identify the outcome of their labours. Similarly, but more specific to the field of craft, in her influential essay on the nature of craft work, Carla Needleman $(1979,3)$ observes that:

'We stand in so peculiar relationship to results that the products of our own hands bring about a confusion in us. We need to know, right away, whether they are good or bad; we need to know, to pin down, to decide, so that we will know how to feel. The fact of our lives is uncertainty, and we crave certainty'

A notable element of craft production is therefore that the craft worker is a recognised individual who is identified as connected to the product they produce (Campbell 2005). Just as a potter (Inkson 1987) or chef (Fine 1996) might see in their pottery or dish an expression of themselves, all of the brewers interviewed expressed a strong connection with the finished ale as a manifestation of their own identity as a brewer. Indeed, Alex deployed a ready parallel with a chef producing meals in a restaurant, saying that:

'You don't feel like that when you work for someone else but when it's your own [...] Exactly the same as a chef, when you've got a customer in a restaurant and tell the waiter or the waitress that meal was lovely please tell the chef, you know, there's nothing better as a chef $[\ldots]$ There's no better kick then going into a pub and seeing someone with your branded glass and thinking what a lovely pint of ale' 
Here the brewer finds in the final beer produced, and in watching those who consume the product in enjoyment, a sense of satisfaction and tangible reward.

The importance of this tangibility of outcomes was particularly prominent for Ryan, who in his mid-twenties was the youngest of brewers interviewed, whose beer would almost exclusively be sold through the pub to which the small brewery was attached and which, although owned by his father, he now took a lead role in managing. He observed that:

'You're making a product and if people like it then that's best. So that's important is being able to see people enjoying it [...] If someone has a pint and doesn't have another then you get a bit worried, but if they have a second one you know it's good you know they're happy'

The importance of the final product, in its tangible materiality, being tasted and appreciated by the customers of the pub is taken, through the validation of seeing a customer try his beer and return for another, as the test of his success as a brewer. For Ryan, this is accentuated by the spatial proximity of the site of his craft, the microbrewery, to the location of its consumption, the pub taproom less than ten metres away.

In many of the interviews, making good beer not just by the brewer's own measure but in terms of others was the central feature of their occupational identity into which all else, their skills and passion, as explored above, could be distilled. This was particularly evident for Jason, for whom taking the voluntary redundancy offered to him by his previous employer led to him setting up a five barrel brewery close to his home town in his early fifties, who explained:

'The funny thing is I think my family understand better now what I do for a living than they ever did when I was at [a previous office based job]. My son is getting to that 
age when he's going out drinking lots, he get's all his mates from rugby drinking our beer, you know, he can say this is his Dad's brewery's ale [laughs] of course they're all after a free cask now for their next house party or whatever but, you know, it's nice and I'm glad they're into it'

Notably, this notion of tangibility in the final product was invoked by the only female brewer interviewed who, in several instances, indicated that her skill and knowledge as manifest in the final well crafted product had, over the years, assuaged some resistance she may have experienced on entering an industry dominated by men at both production and consumption level. Thus, Jane observed that:

'Like it or lump it the main target for drinking beer is man, they drink the beer and they like the styles, but I think having the qualifications and the background I got the respect there that I knew what I was talking about, and making the actual decent beer, it snowballs from that really'

Here, the exhibition of skill and knowledge both in the process and the product is used to establish occupational identity. One of a growing number of 'brewsters' in the British brewery industry (Mesure 2013), Jane reflects how in spite of the male dominance of the brewery and pub industry she has confidence that her beers can 'speak for themselves' in acting as a clear and tangible demonstration of her skills and competence.

Certainly, the above observations concur with Crawford's (2009) suggestions regarding the satisfaction one gains from the 'tangibility' of outcomes and rewards resulting in the greater satisfaction from hands-on manual production. Peter Dormer, in his insightful study The Art of the Maker suggests that 'craft is knowledge that must be demonstrated since it will not easily, if at all, be adequately conveyed through what can be said or written about it' (Dormer 1994, 7). Further still, Dormer (1997) notes that 'the rightness' of what a craftsperson does 
necessarily need the recognition of others. Thus, the brewer's labour results in a tangible material product which can be appreciated tacitly through the taste and senses of both the brewer and the customers who drink the beer. Taken together, this sense of tangibility evidently provided great rewards for the brewers interviewed.

\section{Conclusion}

Through its focus on the occupational identities of brewers, the article has sought to develop an insight into the ways in which brewers understand their work and, importantly, how such is seen as meaningful. The article has therefore contributed to understandings of how craftwork is situated in and through tangible actions and practices. Brewers deployed narratives of skill and passion in developing an occupational identity based on experiencing craftwork as rewarding on several levels. Brewers' narratives of acquiring and using knowledge and skill are sensed and displayed through the tangible process (the smell and sight of the fermentation vessels during brewing) and outcome (the taste and appreciation of the final beer) at work in the brewery setting. Following the likes of Hockey (2009) and O'Connor (2005), addressing the sensory and embodied aspects of worker identity allows for a more nuanced understanding of how individuals relate to their labour and the challenges and rewards of work. The importance of the concept of craft has, therefore, been evident here as a means of addressing the embodiment of skills and competencies alongside emotions such as passion and satisfaction at work in the microbrewery.

The discussion has highlighted the phenomenological aspects of occupational identity which are often overlooked in favour of more abstracted discursive narratives. While brewers did, to some extent, offer stock narratives of their entry into the trade, where their accounts became most energetic was when talking about the brewery as a space with an almost magical coming together of affective attachments, embodied processes and tangible sensory stimuli. All brewers interviewed offered some sense of this being an important reward of the 
job and, for many, one that could easily be contrasted with its lack in previous occupations which were contrasted as being disembodied and unfulfilling.

This article also suggests how current economic problems coupled with advances in theoretical and empirical understandings of affect and embodiment might pave the way for a fruitful return to the earlier concerns of the likes of Marx (1959) and Arendt (1958) on the qualities and rewards or lack of, found in work. Research fostering better understandings of embodied workplace subjectivities, such as those explored in this article, can help to inform current debates concerning the importance and benefits of work and, indeed, the right to rewarding and fulfilling work. Recent research by Hughes (2013), for example, has investigated the alignment of hopes and values of craftswomen working in artisan jewellery making with wider concerns about the restructuring of post-industrial economies and working lives.

While the case of small-scale breweries is admittedly specific, it has nonetheless revealed important insights into the intricacies of occupational identity and workplace subjectivities. These insights add further support to the importance of both theoretical and empirical insights into emotions, embodiments and affects. Importantly, we see here a clear demonstration that any strict dichotomy between physical and mental labour misses the complexity of work which is evidently animated by the richness of a range of cognitive, embodied and sensory features. Indeed, as both Richard Sennett (2008) and Matthew Crawford (2009) have proposed, rediscovering the value of craftwork can prove fruitful in very practical and efficacious ways by returning debates about work and occupational identity to the very human fulfilments of labour which is engaged and rewarding on personal emotional levels as well as in rational economic and wider more politicised economic senses.

\section{Bibliography}


Adamson, G. 2007. Thinking Through Craft. Oxford: Berg.

Anderson, B. and Harrison, P. 2006. Questing Affect and Emotion. Area 38(3): 333-335.

Arendt, H. 1958. The Human Condition. Chicago, IL: University of Chicago Press.

Bain, A. 2005. Constructing an Artistic Identity. Work, Employment \& Society 19(1): 25-46.

Banks, M. 2010. Craft Labour and Creative Industries. International Journal of Cultural Policy 16(3): 305-321

BBPA 2012. The Statistical Handbook 2012/British Beer and Pubs Association. London: Brewing Publications.

Bennet, K. 2013. 'Emotion and Place Promotion: Passionate about a former colefield. Emotion, Space and Society 8: 1-10.

Berner, B. 2008. Working Knowledge as Performance: On the practical understandings of machines. Work, Employment \& Society 22(3): 319-336.

Braverman, H. 1974. Labor and Monopoly Capital: The degradation of work in the twentieth century. New York: Monthly Review Press.

Campbell. C. 2005. The Craft Consumer: Culture, craft and consumption in a postmodern society. Journal of Consumer Culture 5(1): 23-42.

Coombe, R. and Aylwin, N. 2011. Bordering diversity and desire: using intellectual property to market place-based products. Environment and Planning A 43(9): 2027-2042. 
Coulson, S. 2012. Collaboration in a Competitive World: Musicians working lives and understandings of entrepreneurship. Work, Employment and Society 26(2): 246-261.

Crawford, M. 2009. The Case for Working with Your Hands: Or, why office work is bad for us and fixing things feels good. London: Viking.

Daniels, E., Sterling, C. and Ross, E. 2009. Microbreweries and Culture in the Greater Madison Area. Geography, 565.

Dickie, V.A. 2003. Establishing Worker Identity: A study of people in craft work. American Journal of Occupational Therapy 57:250-261.

Dormer, P. 1994. The Art of the Maker: Skill and its meaning in art, craft and design. London: Thames \& Hudson.

Dormer, P. 1997. The Culture of Craft: Status and future. Manchester: Manchester University Press.

Evans, J. 1998. Significant Work: Towards a Framework for the understanding of craft practices. In P. Johnson (ed) Ideas in the Making: Practice in theory. London: Craft Council.

Fine, G.A. 1996. Kitchens: The culture of restaurant work. Berkley: University of California Press.

Flack, W. 1997. American Microbreweries and Neolocalism: "Ale-ing" for a sense of place. Journal of Cultural Geography 16(2): 37. 
Forest, J., Mageau, G. Sarrazin, C. and Morin, E. 2011 "Work is My Passion": The different affective, behavioural and cognitive consequences of harmonious and obsessive passion towards work. Canadian Journal of Administrative Science 28(1): 27-40.

Gunders, J. 2008. Professionalism, place, and authenticity in The Cook and the Chef. Emotion, Space and Society 1(2): 119-126.

Hammersley, M. and Atkinson, P. 2007. Ethnography: Principles and Practice. Abingdon: Routledge.

Hanscomb, J. 1974. The Good Beer Guide. Leeds: Waddingtons.

Hochschild, A. (1983. The Managed Heart: Commercialization of human feeling. Berkley: University of California Press.

Hockey, J. (2009 'Switch On': Sensory work in the infantry'. Sociology 23(3): 477-493.

Hodson, R. 2001. Dignity at Work. Cambridge: Cambridge University Press.

Holden, S. 2011. 'Three Cheers for New Beers: Marketing insights from the birth of boutique brewing in Australia'. Australia \& New Zealand Marketing Academy Conference Proceedings, Perth, Western Australia.

Honore, C. 2004. In Praise of Slow: how a worldwide movement is challenging the cult of speed. London: Orion Books.

Hughes, C. 2013. I draw the line at stringing pearls: The Craftswoman's Imperative and Hopeful Economies. Journal of Cultural Economy 6(2): 153-167. 
Inkson, K. 1987). The craft ideal and the intergration of work: A study of potters. Human Relations. 40(3): 163-176.

Kneafsey, M., Cox, R., Holloway, L., Dowler, L., Venn, L. and Tuomainen, H. 2008. Reconnecting Consumers, Producers and Food: Exploring alternatives. Oxford: Berg.

Marx, K. 1959. Economic and Philosophical Manuscripts of 1844. Moscow: Progress Publishers.

Mesure, S. 2013. Return of the 'brewsters': New beer drinking 'sisterhood' helping to stimulate thriving Real Ale market. The Independent, 12 September 2013.

Metcalf, B. 2002. Contemporary Craft; A brief overview. In J. Johnson (ed) Exploring Contemporary Craft: History, Theory and Critical Writing. Toronto: Coach House Books.

Murnieks, C. Mosakowski, E. and Cardon, M. 2012. Pathways of Passion: Identity centrality, passion, and behavior among entrepreneurs. Journal of Management, Online First.

Neapolitan, J. 1986. Art, Craft, and Art/Craft Segments among Craft Media Workers. Work and Occupations 13(2): 203-216.

Needleman, C. 1979. The Work of Craft: An inquiry into the nature of crafts and craftsmanship. London: Arkana.

O'Connor, E. 2005. Embodied knowledge: The experience of meaning and the struggle towards proficiency in glassblowing. Ethnography 6(2): 183-204. 
Oliver, G. 2011. The Oxford Companion to Beer. Oxford: Oxford University Press.

Palmer, C., Cooper, J. and Burns, P. 2010. Culture, Identity and Belonging in the "Culinary Underbelly". International Journal of Culture, Tourism and Hospitality 4(2): 311-326.

Paxson, H. 2012. The Life of Cheese: Crafting food and value in America. Berkley: University of California Press.

Pink, S. 2009. Doing Sensory Ethnography. London: SAGE.

Polanyi, M. 1967. The Tacit Dimension. London: Routledge and Kegan Paul.

Protz, R. 2011. CAMRA at 40: Still Campaigning for Real Ale and Good Pubs. St Albans: CAMRA Books.

Protz, R. 2013. CAMRA's Good Beer Guide 2014. St Albans: CAMRA Books.

Protz, R. and Millns, T. 1992. Called to the Bar: An account of the first 21 years of the Campaign for Real Ale. St Albans: CAMRA Books Ltd.

Racz, I. 2009. Contemporary Crafts. Oxford: Berg.

Ritzer, G. 1993. The McDonaldization of Society: An investigation into the changing character of contemporary social life. Thousand Oaks, CA; London: Pine Forge.

Robinson, R. and Beesley, L. 2010. Linkages Between Creativity and Intention to Quite: An occupational study of chefs. Tourism Management 31(6): 765-776. 
Russell, B. 2006. The Conquest of Happiness. Abingdon: Routledge.

Sennet, R. 1999. The Corrosion of Character: The personal consequences of work in the new capitalism. New York: W.W. Norton.

Sennet, R. 2008. The Craftsman. London: Allen Lane.

Spracklen, K., Laurencic, J. and Kenyon, A. 2013. 'Mine's a Pint of Bitter': Performmativity, gender, class and representations of authenticity in real-ale tourism. Tourist Studies 13(3): 304-321.

Wainwright, M. 2011. Real Ale Revival Led by Small Breweries. The Guardian, 2 August 2011.

Watson, T. 2009. Narrative, Life Story and Manager Identity: A case study of autobiographical identity work. Human Relations 62(3): 425-452.

Wesson, T. and Figueiredo, J. N. 2001. The Importance of Focus to Market Entrants: A study of microbrewing performance. Journal of Business Venturing 16: 377-403.

Wilk, R. 2006 Fast Food/Slow: The cultural economy of the global food system. Plymouth: Altamira Press.

Wolkowitz, C. 2006. Bodies at Work. SAGE: London. 